\title{
Saberes e verdades acerca da enfermagem: discursos de alunos ingressantes
}

\author{
Knowledge and truths about nursing: discourse of new students
}

Saberes y verdades acerca de la enfermería: discursos de alumnos novatos

\author{
Beatriz Sebben Ojeda', Olga Rosaria Eidt', \\ Simone Canabarro', Valéria Lamb Corbellini', Marion Creutzberg" \\ 'Pontifícia Universidade Ctólica do Rio Grande do Sul, Faculdade de Enfermagem, Nutrição e Fisioterapia. PortoAlegre, RS \\ I'Iniversidade Federal do Rio Grande do Sul, Departamento de Enfermagem. Porto Alegre, RS
}

Submissão: $24 / 11 / 2006$

Aprovação: 13/09/2007

\section{RESUMO}

Trata-se de um estudo de abordagem Qualitativa, com o Qual se propõe analisar regimes de verdades Que perpassam a profissão Enfermagem, manifestados por alunas(os) ingressantes no Curso de Graduação, 2004/2, 2005/l e 2005/2. Como opção metodológica para a análise dos dados foi realizada a Análise de Discurso, utilizando-se referenciais de Michel Foucault. Nesse contexto de análise e discussão emergiram três grandes temáticas: atravessamentos de saberes de gênero na prática da Enfermagem; a Enfermagem como saber hierarQuizado; o fazer como poder, no cotidiano acadêmico e profissional da Enfermagem. Evidenciaram-se concepções sociais Que são atravessadas por saberes invisíveis Que legitimam práticas de saúde e de enfermagem, tornando-as inquestionáveis.

Descritores: Enfermagem; Identidade de gênero; Educação em enfermagem.

\section{ABSTRACT}

It is a study with a Qualitative approach that proposes to analyze truths regimes that pass by and along Nursing as a profession, as manifested by students entering in the Graduate Course 2004/2, 2005/1 and 2005/2. The Discourse Analysis has been used as a methodological option for analyzing the data, under Michel Foucault's approaches. Three great themes have come out of such context of analysis and discussion: the traversing of gender knowledges in Nursing practice; Nursing as a knowledge made hierarchical; making as a might in Nursing's academic and professional day-by-day. Social conceptions became self evident, going through invisible knowledges that legitimate health and nursing practices, making them unquestionable.

Descriptors: Nursing; Gender identity; Education, nursing.

\section{RESUMEN}

Se trata de um estúdio de abordaje cualitativo, Que propone analizar regímenes de verdades Que sobrepasan la profesión Enfermería, manifestados por alumnas(os) Que ingresan en el Curso de Graduación, 2004/2, 2005/1 , 2005/2. Como opción metodológica para el Análisis del Discurso, utilizándose referencias de Michel Foucault. Em este contexto de análisis y discusión emergieron tres grandes temáticas: cruzamiento de saberes de género en la práctica de Enfermería; la Enfermería como un saber jerarquizado; el hacer como poder en el cotidiano académico y profesional de Enfermería. Se evidenciaron concepciones sociales que son atravesadas por saberes invisibles que legitiman prácticas de salud y de enfermería, tornándolas incuestionables.

Descriptores: Enfermería; Identidad de género; Educación en Enfermería.

Correspondência: Beatriz Sebben Ojeda. Av. Ipiranga, 6681 Prédio 12, Bloco A, 8 o andar. Partenon. CEP 90619900 - Porto Alegre. RS. 


\section{INTRODUÇÃO}

As subjetividades Que compõem as profissões da Área de Saúde são permeadas de saberes, tidos como verdades naturalizadas e inquestionáveis que perpassam as relações sociais. Sob esse aspecto destaca-se que toda sociedade possui regimes de verdades Que determinam regras, legitimam ou desconsideram práticas, dizem e impõem diferentes valorizações sociais ${ }^{(1)}$. As práticas profissionais e acadêmicas das diferentes profissões são atravessadas por saberes de gênero Que desenham e redesenham papéis historicamente construídos entre homens e mulheres. Diante da amplitude e complexidade Que envolvem estudar o cenário multiprofissional da Saúde, o presente estudo centra-se na análise da Enfermagem como prática naturalizada feminina, constituindo-se, provavelmente, em uma das profissões mais antigas, exercidas por mulheres.

A prevalência feminina na Enfermagem é uma realidade no cenário acadêmico, como ilustra o registro de matriculadas(os) do Curso de Graduação da Pontifícia Universidade Católica do Rio Grande do Sul em Que o número de mulheres ultrapassa a $85 . \%^{(2)}$. No âmbito do trabalho, segundo dados do Conselho Regional de Enfermagem, de 11931 profissionais inscritos, a prevalência feminina é de $92,36 \%{ }^{(3)}$. Esses dados ilustram a realidade nacional e uma tendência mundial dessa profissão, despertando a necessidade de estudos Que possibilitem evidenciar como determinados saberes acerca desta Área vêm sendo socialmente construídos e como se articulam às relações sociais das práticas em Saúde.

Estudos de gênero discutem Que profissões ditas femininas, a exemplo da Enfermagem, mostram-se institucionalizadas como práticas sociais próprias de mulheres, trazendo às práticas discursivas e não discursivas a concretização de tais saberes ${ }^{(4-8)}$. Contudo, destaca-se Que o enfoque da construção social da Enfermagem não se limita à análise de gênero, uma vez Que nas relações sociais podem-se visualizar atravessamentos de diferentes saberes, dentre eles econômicos, políticos, culturais Que organizam e normalizam essas prática dentre elas as referentes à saúde ${ }^{(9)}$. A análise de diferentes saberes engendrados na construção histórica da Enfermagem vai em busca de rupturas e (re)construções sociais, no âmbito da Saúde e da sociedade, merecendo, portanto, um destacado espaço de discussões que perpassem a formação das(os) profissionais, envolvendo professores e estudantes, bem como entre as(os) Que vivenciam o cotidiano das relações interprofissionais em Saúde.

Com essa perspectiva, pelo presente estudo analisam-se discursos que circulam e são produzidos, acerca da Enfermagem, pelas políticas sociais, pelas Instituições desta Área, pela mídia, pelas Instituições de ensino, sobretudo as Universidades, como responsáveis históricas pela (re)produção de conhecimentos e verdades instituídas na Área da Saúde e na Sociedade, ou seja, os saberes acerca da Enfermagem Que circulam não somente no universo da Saúde, mas também em diferentes instâncias da sociedade. Optou-se em dar voz a alunas(os), recém ingressantes no Curso de Graduação em Enfermagem, Que trazem consigo saberes e verdades Que circulam nos espaços de convivência social, bem como discursos Que circulam nos meios sociais, extraindo enunciados Que se constituem regimes de verdades acerca da Enfermagem.

Buscando abrigo nas orientações das Diretrizes Curriculares para formação de profissionais de Saúde, incluindo nesses os da
Enfermagem, entende-se Que o presente estudo contribuirá para desenvolver nas(os) alunas(os) atitudes críticas e reflexivas acerca das práticas Que conformam a Área da Saúde, suas (re)construções cotidianas em Que perpassam redes de relações sociais.

Assim, com o presente estudo tem-se como objetivo, analisar regimes de verdade Que perpassam a profissão Enfermagem manifestados por alunas(os) ingressantes no Curso de Graduação.

\section{MÉTODO}

O estudo realizado é de abordagem Qualitativa pela Qual se propõe analisar criticamente as concepções sociais expressadas por alunas(os), acerca da Enfermagem. Integraram o estudo alunas(os) ingressantes no Curso de Graduação do ano de 2004/2 e 2005/ I e 2005/2 Que aceitaram participar, em horários extra-classe. O estudo foi desenvolvido, respeitando-se os procedimentos éticos previstos pelo Conselho Nacional de Saúde. Foi aprovado pelo Comitê de Ética em Pesquisa da PUCRS e considerada a Questão da vulnerabilidade, por serem alunas(os) das professoras pesquisadoras. Após esse processo as(os) participantes assinaram um Termo de Consentimento Livre Esclarecido.

O convite para participar do estudo ocorreu em um momento coletivo de sala de aula, Quando foi apresentado o Projeto de Pesquisa. A coleta de dados foi realizada por meio da técnica de grupos focais. Esta abordagem tem sido intensificada, especialmente na pesquisa Qualitativa, com interesses voltados à investigação do social, pois oferece ao pesQuisador a oportunidade de conhecer a opinião, o pensamento, sentimento e ações de um grupo determinado de pessoas frente a um fenômeno social ${ }^{(10)}$.

Os participantes dos seis grupos focais realizados foram agendados previamente e o número médio foi de sete a dez alunas(os). Os grupos focais foram conduzidos pelas pesquisadoras e as falas, gravadas, sendo, posteriormente, transcritas para análise. A duração dos encontros foi de 40 a $60 \mathrm{mim}$.

A discussão do grupo se deu de maneira semi-estruturada com uma pergunta inicial: o Que vocês pensam sobre a Enfermagem? Outras perguntas surgiram: o Que significa para vocês a palavra enfermeira? e a palavra enfermeiro? Como vocês vêem a enfermeira e o enfermeiro no espaço social? $\mathrm{O}$ Que vocês vieram buscar na Enfermagem? A dinâmica do grupo não se restringiu à simples alternância entre perguntas e respostas das(os) participantes, pois a cada Questionamento lançado observou-se o desencadeamento de discussões e depoimentos que ampliaram possibilidades de análises do fenômeno social em estudo.

Para a análise dos dados optou-se pela Análise de Discurso sob olhar de Foucault. A partir dos discursos das(os) participantes, ficou claro Que concepções sociais circulam de um determinado saber - na forma de objeto, de estratégia ${ }^{(1)}$, presentes no âmbito acadêmico e profissional. A construção da análise se deu nos regimes de verdade ${ }^{(1)}$ constantes nos mesmos discursos, a partir dos Quais se elegeram as temáticas, desenvolvidas em narrativas textuais, integradas, também, a discussões teóricas.

\section{RESULTADOS E DISCUSSÃO}

A análise vai ao encontro dos discursos, como algo Que diz como as coisas são, o Que significa dizer Que as sociedades e culturas 
são dirigidas por poderosas ordens discursivas Que regem o Que deve ser dito e o Que deve ser calado e os próprios sujeitos não estão isentos desses efeitos, pois eles são constituídos e constituidores dessas verdades ao aceitarem-nas, no mínimo, como tal ${ }^{(11)}$.

A análise e a discussão dos dados são abordadas em três temáticas: 1) atravessamentos de gênero na prática da Enfermagem; 2) a Enfermagem como saber hierarQuizado; 3) o fazer como poder no cotidiano acadêmico e profissional da Enfermagem. Contudo, a escolha destas temáticas, longe de esgotar possibilidades de análise, buscou desacomodar verdades presentes no contexto social da Enfermagem a fim de serem vizibilizadas e (re)construídas no universo acadêmico e profissional.

\section{Atravessamentos de Saberes de Gênero na Prática da Enfermagem}

No Brasil, a ampliação estatística da educação superior feminina é expressiva. Recente publicação acerca da trajetória da mulher na Educação Brasileira, no período de 1996 a 2003, aponta um salto Quantitativo de homens e mulheres matriculados na Graduação, mas ressalta Que a diferença entre os sexos, Que era $8,7 \%$, em 1996, a favor das mulheres, cresceu para 12,8\%, em 2003. Destaca, também, Que o crescimento da presença das mulheres no Ensino Superior se dá em todas as regiões do País ${ }^{(12)}$.

Outro dado Que chama atenção na publicação citada é Que a Enfermagem encontra-se entre os dez cursos com maiores percentuais de matrículas do sexo feminino; de 92.134 matriculados, $84,7 \%$ são mulheres, embora se possa dizer Que a ampliação masculina nesta Área também se mostra evidente, pois nesse ranking ela está em $9^{\circ}$ lugar. Os maiores percentuais femininos ocorrem nos Cursos de Serviço Social, Fonoaudiologia e Nutrição. O estudo também apresenta os dez maiores percentuais de matrícula do sexo masculino, entre eles em Mecânica, Construção Civil, Transporte e Eletrônica.

Ao trazer em evidência tais dados estatísticos ressalta-se Que papéis femininos e masculinos, historicamente representados em nossa sociedade, perpassam conceitos e ideais construídos no viver da pessoa, dentre esses, saberes próprios de gênero, embora já se evidencie uma realidade em transformação que busca, pelo menos no discurso, superar essa diferença. Contudo, apesar dos evidentes atravessamentos de saberes de gênero, presentes nas diferentes profissões, na análise das relações sociais se faz necessário o alerta para relativizar posições maniQueístas, pelo risco de se encobrir a complexidade que ultrapassa as relações entre profissionais homens e profissionais mulheres ${ }^{(13)}$.

O ingresso das mulheres à formação superior, incluindo a PósGraduação, ampliou sua participação nas profissões intelectualizadas, embora sempre houvesse relatos de discriminação, fundamentada na diferenciação sexual ${ }^{(14)}$. Como decorrência, evidenciaram-se diferentes oportunidades profissionais entre homens e mulheres e hegemonia política masculina nas Instituições, como ilustra o discurso a seguir:

[... Jeles pedem e comandam: 'vocês, a Enfermagem era uma coisa inferior aos homens daquela época, a gente é médico, a gente sabe, vocês são enfermeiros'! acho Que vem daí o porquê de haver mais homens na Medicina e mulheres na Enfermagem./.../(GI)
No Brasil, as pedagogias foram o primeiro e, por tempo, o único espaço concedido às meninas no Ensino Público, embora também estivessem integradas a determinantes de classes sociais e étnicos. As justificativas deste processo de Educação sempre estiveram alicerçadas no seu papel materno ${ }^{(15)}$. A ampliação da educação da mulher, ao final do século XIX, mescla-se à modernização da sociedade, à necessidade de instituição de medidas de higienização da família, buscando a prevenção de doenças e à construção da cidadania dos jovens. Nesse processo pode-se visualizar, ao logo da história da educação das mulheres, a instituição de doutrinas, representações e práticas sociais constituidoras da subjetividade masculina e feminina, mostrando, nessas raízes, práticas sociais atuais:

[...] A Enfermagem é tão feminina pelo instinto afetivo da mulher; talvez por isso tenha menos homens porQue a maioria não consegue ser sensível. [...la sociedade se organiza sendo o homem mais forte e a mulher mais frágil.[...](G4)

Da observação dos grupos realizados ressalta-se Que a participação masculina foi ao encontro de verdades e mitos Que cercam o mundo da Enfermagem apesar de o número de participantes masculinos ter sido peQueno. Quanto à participação feminina, as mulheres mostraram-se mais exaltadas, mais preocupadas com a Questão de posição, cargos, história; já os homens manifestaram maior preocupação com a imagem da figura masculina no âmbito da Enfermagem, com Qual seria seu papel em um universo eminentemente feminino. O papel masculino na enfermagem também foi debatido por evidenciarem-se (pré)conceitos sociais Que relacionam o homem e enfermagem com o homossexualismo. Também foi debatido o tema de a mulher estar "invadindo" o universo masculino a exemplo da Medicina Que hoje conta com um número significativo de mulheres.

Ao trazer à tona tais observações, dá-se visibilidade a determinados regimes de verdade Que se expressam nas relações sociais, sejam elas acadêmicas, profissionais, familiares e Que necessitam ser integradas aos dados coletados.

A história das mulheres expressa que, ao longo dos tempos, instituiu-se seu papel natural de cuidadora da família e do espaço doméstico.

[...]. O papel de cuidado, até da maternagem, por ser essa Questão mais delicada, mais afetiva é uma maneira de se expressar nesta profissão, o lado afetivo./.../(GI).

Esses papéis, historicamente construídos, aparecem transversalizados nas profissões de cuidado, o Que permite conjugar a sua construção social à construção social de gênero, a exemplo da Enfermagem Que, como já mencionado, constitui um "verdadeiro gueto ocupacional feminino"(16)

Assim, é possível visualizar caminhos distintos traçados entre homens e mulheres, iniciando-se pela educação familiar. Os saberes de gênero mostram-se engendrados em todas as relações sociais:

[...] O homem não consegue prender seu sentimento e aí a mulher se torna aQuela peça Que tem Que cuidar, manter, mandar falar para fazer certo.[.../(G2). 
Na Idade Média, a educação das meninas dava-se como extensão dos hábitos e costumes, ou seja, para perpetuação do espaço doméstico; já os meninos de uma certa condição social, a partir dos sete anos eram encaminhados a internatos ou outros estabelecimentos Que lhe propiciassem preparo para a vida na sociedade, fora do $\operatorname{lar}^{(17)}$.

Sob esse aspecto pode-se analisar Que a organização social se dá na ótica da vida pública e privada, evidenciando-se uma racionalidade em Que homens e mulheres sofrem efeitos desiguais: atributos masculinos ligados à esfera pública, ao trabalho, à provisão familiar e feminino, à esfera privada, com responsabilidade de gerenciamento do espaço familiar, incluindo filhos e a preservação da força de trabalho masculino ${ }^{(13)}$.

O regime de verdade Que institui papéis femininos e masculinos no universo do trabalho ${ }^{(1)}$ é assim referido:

[.... A gente espera do homem um cargo mais alto,como médico.

Percebo Que as pessoas respeitam muito mais o enfermeiro(homem), tanto os médicos como técnicos.[.../(GI).

Contudo, esse discurso assinala Que, além dos papéis masculinos e femininos, evidenciam-se saberes profissionais Que se mesclam aos saberes de gênero, hierarQuizando profissões.

[...]se vê isso com o médico nos andares e no setor cirúrgico, eles preferem lidar com instrumentadora mulher, enfermeira porque eles podem exercer seu poder; Quando entra um instrumentador homem ele tem comportamento bem diferente, muda o tom e o jeito de falar [...] (G2)

A hierarquia de gênero pode ser visualizada no âmbito da Medicina/homem e Enfermagem/mulher.

[... eu fui com a enfermeira visitar os pacientes nos Quartos, ela falava com eles e, principalmente as mulheres, respondiam olhando para mim, não para enfermeira, elas achavam Que eu era o médico./.../(Gl).

Mas Quando ocorre a inversão de gênero, ou seja, mulher/ Medicina e homem/Enfermagem, a valorização da cientificidade dos campos é Que ganha evidência ${ }^{(18)}$.

As estratégias de poder Que mobilizam homens e mulheres também estão presentes em profissionais da mesma Área:

[... Inós enfrentamos preconceitos Quando ingressamos na Enfermagem. Até na brincadeira está muito ligada a Questão do homossexualismo: porQue tu Queres fazer Enfermagem? vai fazer Qualeuer outra coisa!/.../(GI).

Esse discurso põe em evidência a concepção de saúde ainda fortemente arraigada ao modelo hospitalocêntrico controlado por mulheres.

[...] Até das enfermeiras ouço, Quando falo: 'to fazendo Enfermagem!', ela responde: 'é muito bom para gente, precisamos de alguém que faça força, tem Que ter alguém Que carregue peso, ter Que passar paciente'. Então, o homem ainda dentro da Enfermagem é uma ferramenta, é um guindaste. Para os homens, o pessoal Que não é da Área, Quando eu falo que faço Enfermagem eles fazem menção de gay. Está muito ligado à Questão do homossexualismo, que é questão do cuidado ter afetividade $[\ldots](\mathrm{Gl})$

A presença masculina na enfermagem ainda é vista por homens e mulheres, como uma prática não ligada à natureza masculina.

\section{A Enfermagem como Saber Hierarquizado}

O tema saber, nessa seção, refere-se aos saberes científicos, ou não, Que conformam as práticas da enfermagem e as legitimam nos seus regimes de verdade ${ }^{(1)}$.

O processo de medicalização da saúde toma forma a partir do século XVIII Quando a Medicina passa a assumir um caráter, não só clínico, mas também social. Segundo Foucault ${ }^{(20)}$, foram Quatro processos Que caracterizaram o modelo da época e Que parecem estar presentes nas práticas sociais: o surgimento da autoridade médica, Que está além da autoridade do saber, Que se legitima como pessoa erudita, como pessoa com conhecimento diferenciado.

[... porque eu tenho em mente que a Medicina é muito mais minuciosa, difícil também, não Que a Enfermagem não seja também, mas no meu conceito é menos [...] (G2).

A autoridade médica legitima-se como autoridade social, cabendo-lhe decisões relativas à sociedade (na cidade, no bairro, na Instituição, etc.). Evidencia-se o surgimento de um campo de intervenção da Medicina distinto das enfermidades: o ar, a água, as construções, os terrenos convertem-se em objeto da Medicina. Introduz-se um aparato de medicalização coletiva Que se concretiza com a introdução do novo hospital e o surgimento de mecanismos de administração médica, com a inclusão de registros de dados, comparação, estabelecimento de estatísticas, dentre outros. É neste modelo que a Medicina torna-se o centro do saber em Saúde e é onde se dão "lutas" nas relações entre as diferentes profissões desta área.

[...] o enfermeiro, não é visto como ciência e sim como prática apenas, eu vejo Que isso está mudando; na minha família mesmo tinha uma outra noção antes de eu entrar na faculdade aí [...] é muito maior do que a gente pensa [...] (G3) .

Relações hierárquicas entre a Medicina e a Enfermagem parecem perpassar a história da Saúde moderna. Lunardi Filho ${ }^{(21)}$ assinala Que só foi possível para a Enfermagem incorporar o conhecimento, dito científico, a partir de seu acesso ao conhecimento da Saúde de domínio dos médicos, mesmo que de modo restrito, embora ainda se mantivessem presentes nessas Áreas relações de domínio e submissão, como expressa o discurso:

[...] o médico vem para cima do enfermeiro porque o paciente dele não recebeu o cuidado adequado, ele só transmite a reclamação para o técnico, mas perdeu, eu acho, o contato com o paciente perdeu o cuidado, o enfermeiro é um cuidador burocrático, cuidador de papéis. [...]. (GI)

As relações humanas determinam como é exercida a conduta de 
um em relação ao outro, tornando visível aQuilo Que se autoriza a falar, o jogo de verdade Que se institui. Se a(o) enfermeira(o) é cerceada por alguém, por um grupo ou mesmo pela Instituição, não significa Que ela(ele) também não exerce essa atitude de dominação em relação ao outro, mostrando Que "[...] essas relações de poder são, portanto, móveis, reversíveis e instáveis" (22).

[... Que já iniciou de baixo e daquela começou de cima; aquela Que entra direto na faculdade é dita enfermeira burocrata. Ela separa as coisas, se ela tiver Que dar um banho de leito, retirar comadre e fazer tudo ela faz e a outra não./.../(G5)

As relações de poder parecem fervilhar no cotidiano das(os) profissionais de Saúde alicerçadas nos regimes de verdades Que hierareuizam práticas tornando-as distanciadas umas das outras, ou seja, fragmentadas. Para Foucault ${ }^{(1)}$, "múltiplas relações de poder perpassam, caracterizam, constituem o corpo social "; essas relações de poder produzem e acumulam saberes Que circulam e constituem discursos de verdades. Somos submetidos, pelo poder, à produção da verdade e só podemos exercê-lo, produzindo verdades.

Nas profissões da Saúde, ditas femininas, o cuidado de si a que Foucault ${ }^{(23)}$ se refere, parece adeuirir dimensões estritamente voltadas para a execução, para o controle de hábitos e costumes, ditos saudáveis, como a extensão de cuidados maternos, Que necessitam da vigilância dessas(es) profissionais, mas Que parecem se distanciar do lugar político Que institui esses deveres e obrigações $^{(23)}$. As funções gerenciais parecem mostrar-se distanciadas dessas prescrições:

[.... pelo gerenciamento, a Enfermagem se tornou muito burocrata, a enfermeira como profissão feminina acaba por ficar no controle dos papéis e se distanciando do cuidado, dos pacientes [...] (G I)

A centralidade da(o) enfermeira(o), nos contextos organizacional e assistencial é referida, destacando Quatro características: ser a(o) detentora de Quase toda totalidade de informações; ser a(o) organizadora(r) de todo o ambiente de cuidado, ser a(o) guardiã(ão) das normas e rotinas institucionais e ser a(o) organizadora(r) da assistência ${ }^{(21)}$. Os discursos a seguir expressam tal realidade:

[...] gerenciar já é um cuidado, o gerenciamento do ambiente é um cuidado com este ambiente, disposição, as coisas, a higiene ela está cuidando [.../(G I)

[...] Mas tem bastante coisa para eles fazerem, eles ficam presos com os papéis. A maioria deles vão ali, têm o contato direto Quando é extremamente necessário, é procedimento do enfermeiro, Que não tem como passar para o técnico [...] (G I)

[... Quando fui visitar a emergência a enfermeira nem pôde ficar direito comigo; a maior parte do tempo ela ficou das $9 \mathrm{~h}$, a hora Que cheguei, até I 2 h30min, a hora Que fui embora ela estava fazendo a parte burocrata. [...] (G3)

Nos discursos apresentados evidenciam-se características eminentemente gerenciais da(o) enfermeira(o) no cotidiano do trabalho em Instituições de Saúde, sobretudo as hospitalares, contrapondo-se aos ideais de um(a) enfermeiro(a) assistencial e cuidador(a), preconizado em sua formação acadêmica.

[... Cuidando dos papéis, passando para a chefe, deixando de lado o cuidado. Estão deixando para os técnicos, isso não é função deles, de analisar o Que está acontecendo no ambiente Que é função do enfermeiro/.../(GI)

Esta temática foi fortemente abordada em determinados grupos onde se mesclavam alunos trabalhadores de enfermagem, o Que incita à necessidade de análises sobre regimes de verdade Que perpassam as relações entre as diferentes categorias de enfermagem.

\section{O Fazer como Poder no Cotidiano Acadêmico e Profissional da Enfermagem}

Quanto à organização social de trabalho, a Enfermagem tem suas práticas fragmentadas, onde circulam relações de poder, no cotidiano acadêmico e profissional. Visualizar-se o regime de verdade de Que bom profissional, em Qualquer das categorias de Enfermagem, significa ter domínio técnico, ser bom executor de técnicas. O conhecimento Que sustenta este fazer parece invisível ou não considerado. Essas concepções aparecem fortemente presentes ${ }^{(4)}$ nas práticas em Saúde, evidenciando a dicotomia entre a Ciência como trabalho intelectual, pensante, decisório (atribuída à Área médica, socialmente concebida como masculina) e o fazer técnico, como trabalho manual, não pensado, Que requer habilidade, docilidade, sensibilidade (atributos imprescindíveis para profissões cuidadoras como Enfermagem, Nutrição naturalizadas como femininas).

A instituição dessa dicotomia se dá nas Ciências Naturais, decorrente da cultura americana e européia Que ideologicamente separam o trabalho intelectual e manual (Ciência e Tecnologia), valorizando o trabalho intelectual, em detrimento do manual. Nas diferentes categorias de enfermagem essas concepções, como regimes de verdade designam e impõem à(o) enfermeira(o) a necessidade prioritária de domínio técnico, relegando, para segundo plano, necessidades de desenvolvimento intelectualizado, atributo indispensável a outras profissões, a exemplo da Medicina.

[... eu percebo Que tem muita diferença de enfermeiras em relação àQuelas Que nunca viram uma enfermagem pela frente $e$ de repente caem dentro de uma faculdade e depois vão para uma profissão[.../(GI)

Entretanto, parece que esta hierarquização que dicotomiza as práticas entre saber e fazer também se apresenta no universo das categorias de enfermagem:

[...] Infelizmente (a enfermagem) ainda não é bem vista, as pessoas não diferenciam muito o Que é o auxiliar, o técnico, o enfermeiro, além disso, pensam que todo mundo que se forma vai limpar bunda de paciente[... /(G3)

Esse regime de verdade também perpassa o universo acadêmico onde se estabelecem relações de poder entre as(os) acadêmicas(os) Que exercem a profissão de técnica(o) de enfermagem e as(os) 
demais acadêmicas(os). Estas relações são visíveis em sala de aula, onde as(os) Que têm experiências na enfermagem dominam as discussões, trazendo em evidência a necessidade de domínio técnico para ser boa(bom) enfermeira(o).

\section{[...] há uma cobrança dos próprios colegas. Quem é técnico e} entra numa faculdade de Enfermagem os colegas dizem: vê se tu não perde o vínculo com a gente depois Que tu fores chefe, vê se continua pegando junto com a gente [...](G4).

Nos discursos apresentados observa-se Que a experiência prévia das(os) alunas(os) na Área de Enfermagem, na formação acadêmica, exerce certo status em relação aos alunos Que não a possuem.

Ao refletir sobre essas Questões, reporta-se aos três domínios - do saber, do poder e da ética, Que Foucault(24) ${ }^{(20 l o c a}$ como estabelecimento nas relações do sujeito sobre as coisas, sobre os outros e sobre si. Araújo ${ }^{(25)}$ suscita a idéia de Que a Questão central está focalizada em como nos constituímos como sujeitos de nosso saber, Que exercem ou sofrem relações de poder e, a partir daí, Que ações se toma como sujeitos morais, como estilo de vida, uma ética, uma estética da existência, exemplificado no discurso abaixo:

[...] Acho que depende de cada um, eu escolhi Enfermagem por ser Área da Saúde e eu gosto. Acho uma Área bonita, interessante, adquirir conhecimento. Acho que foi isso que me fez escolher Enfermagem, mesmo sem ter noção de Quando comecei o curso do que era Enfermagem. Agora que está no meio do semestre, Quase terminando eu vi que é realmente isso que eu Quero[...] (GI)

O fato de como se é constituído, como sujeito do saber, possibilita vislumbrar outras trilhas como práticas de liberdade, o Que Foucault sinaliza como sendo cuidar de si, para se conhecer e romper com estruturas, com hegemonias de poderes.

Talvez, um dos caminhos seja o de problematizar, cada vez mais, Questões referentes às relações de poderes instituídos na Área da Saúde, assim como redesenhar, no ensino de Graduação, práticas de saúde Que permitam ao aluno vislumbrar outras possibilidades como um sujeito Que também é co-partícipe dessa realidade social ${ }^{(26)}$

\section{CONSIDERAÇÕES}

Com a temática deste estudo, embora centrada na Enfermagem, propõe-se trazer à discussão problemáticas invisíveis, presentes no universo acadêmico, e Que perpassam as relações com professores, alunos, profissionais de diferentes Áreas. Entende-se Que os conflitos e Questionamentos oriundos das relações interprofissionais na Saúde, nesse momento histórico, têm, em seus meandros, as mudanças dessas últimas décadas Que visibilizaram as diferentes profissões, traçando nova organização das práticas em saúde, mobilizando saberes profissionais e saberes de gênero.

Ao discutir a temática Que envolve a construção social da Enfermagem depara-se com a constituição de saberes Que se mesclam ao saber científico e às práticas cotidianas definindo diferentes papéis sociais nas profissões da Saúde. Entende-se que esses saberes são relações de poder Que vão se constituindo como num jogo de verdades, Que vão se formando, sendo formados nas relações entre os profissionais de Enfermagem bem como nos demais profissionais de Saúde.

Nesses jogos de verdade evidenciam-se diferenças entre o masculino e o feminino, incitando à idéia de separação/exclusão. Não se trata, aQui, de analisar estas diferenças como uma construção hierárQuica nas relações homens e mulheres, e sim, de olhá-las como exclusões e distanciamentos para redesenhar caminhos Que ultrapassem o olhar de gênero em busca da conciliação, da liberdade e da inclusão.

Desta forma, ao buscar os corpos anônimos nos discursos, como os dos ingressantes do curso de Enfermagem, torna-se importante Questioná-los e dar visibilidade a outros silenciados, propiciando, assim, a constituição de outros saberes a fim de encontrar novos caminhos Que possam desenhar uma nova geografia nesses territórios ainda desconhecidos ou pouco explorados.

\section{REFERÊNCIAS}

1. Foucault M. A arqueologia do saber. $6^{\mathrm{a}}$ ed. Rio de Janeiro (R)): Forense Universitária; 2002.

2. Pontifícia Universidade Católica do Rio Grande do Sul, Documentos Acadêmicos. Porto Alegre (RS): PUCRS; 2005.

3. Conselho Federal de Enfermagem - COFEN. 2006 [citado em 2006 jun 06]. Disponível em: URL: http:// www.portalcofen.org.br

4. Gergen MMC. O Pensamento feminista e a estruturação do conhecimento. Brasília (DF): Rosa dos Ventos; 1988.

5. Lopes MIML. O sexo do hospital. In: Lopes MJML, Meyer DE, Waldow VR, organizadoras. Gênero \& Saúde. Porto Alegre (RS): Artes Médicas; 1996. p. 76-105.

6. Meyer DE. A formação da enfermeira na perspectiva de gênero: uma abordagem sócio-histórica. In: Waldow VR, Lopes MJM, Meyer DE, organizadoras. Maneiras de cuidar, maneiras de ensinar: a enfermagem entre a escola e a prática profissional. Porto Alegre (RS): Artes Médicas; 1995. p. 63-78.
7. Strey MN. Aprendendo a ser inferior: as hierarquias de gênero. In: Strey MN, Lira AV, Ximenes LMS. Gênero e Questões culturais: a vida de mulheres e homens na cultura. Recife (PE): Ed. Universitária; 2002. p. 2 1-32.

8. Tosi LA. Ciência e a mulher. Ciência Hoje 1991; 13(75): 26-32.

9. Ojeda SB. A tecedura das relações saber-poder em saúde: Matizes de saberes e verdades [tese]. Porto Alegre (RS): PUCRS; 2004.

10. Roso $\mathrm{A}$. Grupos focais em psicologia social: da teoria à prática. Rev Psicol 1997; 28(2): 1 55-69.

11. Foucault M. Microfísica do poder. $15^{\mathrm{a}} \mathrm{ed}$. Rio de Janeiro (RI): Graal; 2000.

12 Godinho T, Ristoff D, Fontes A, Xavier IM, Sampaio CEM, organizadores. A Trajetória da mulher na educação brasileira 1996-2003. Brasília (DF): INEP; 2006.

13 Moreira MCN. A Fundação Rockefeller e a construção da identidade profissional de enfermagem no Brasil na Primeira 
República. História, Ciências, Saúde 1999 ; (3): 62 I-45.

14 Scott J. Gênero: uma categoria útil de análise histórica. Educação e Realidade 1990; 16(2): 5-22.

15 Louro GL. Mulheres na sala de aula. In: Del Priore M. História das mulheres no Brasil. São Paulo (SP): Contexto; 2000. p. 443-81.

16 Fonseca TMG. De mulher a enfermeira: conjugando trabalho e gênero. In: Lopes MJM, Meyer DE, Waldow VR. Gênero e saúde. Porto Alegre (SP): Artes Médicas; 1996. p. 63-75.

17 Ariés P. História social da criança e da família. $2^{\text {a }}$ ed. Rio de Janeiro (RI): Guanabara; 1986.

18 Bandeira L, Oliveira EM. Representações de gênero e moralidade na prática profissional da enfermagem. Rev Bras Enferm 1998; 5 I (4): 677-96.

19 Girardi SN, Carvalho CL. Mercado de trabalho e regulação das profissões de saúde. In: Negri B, Faria R, Viana ALA. Recursos humanos em saúde: política, desenvolvimento $\mathrm{e}$ mercado de trabalho. Campinas (SP): UNICAMP; 2002

20 Foucault M. La vida de los hombres infames. La Plata (ARG): Caronte Ensayos; 1993

21 Lunardi Filho WD. O mito da subalternidade do trabalho da enfermagem à medicina. Pelotas (RS): Editora e Gráfica Universitária-UFPel; 2004.

22 Foucault M. Ditos e Escritos V: ética, sexualidade e política. São Paulo: Florense Universitária; 2004.

23 Foucault M. Resumo dos cursos do College de France 19701982. Trad Daher A. Rio de Janeiro: Jorge Zahar; 1997.

24 Foucault M. Ditos e Escritos IV: estratégia, poder-saber. São Paulo: Florense Universitária; 2003.

25 Araújo IL. Foucault e a crítica do sujeito. Curitiba (PR): UFPR; 2000.

26 Corbellini VL. O disciplinamento dos saberes como jogos de verdades no ensino de Graduação em Enfermagem [tese]. Porto Alegre (RS): PUCRS; 2005. 